\title{
Stereoselective Ring-Opening (Co)polymerization of $\beta$-Butyrolactone and $\varepsilon$-Decalactone Using an Yttrium Bis(phenolate) Catalytic System
}

\author{
Jiraya Kiriratnikom ${ }^{1,2,3}$, Carine Robert ${ }^{3}$, Vincent Guérineau ${ }^{4}$, Vincenzo Venditto ${ }^{5 *}$ and \\ Christophe M. Thomas ${ }^{3 *}$
}

${ }^{1}$ Department of Chemistry, Faculty of Science, Mahidol University, Bangkok, Thailand, ${ }^{2}$ Department of Materials Science and Engineering, School of Molecular Science and Engineering, Vidyasirimedhi Institute of Science and Technology, Rayong, Thailand, ${ }^{3}$ Chimie ParisTech, PSL University, CNRS, Institut de Recherche de Chimie Paris, Paris, France, ${ }^{4}$ CNRS UPR2301, Institut de Chimie des Substances Naturelles, Université Paris-Sud, Université Paris-Saclay, Gif-sur-Yvette Cedex, France, ${ }^{5}$ INSTM Research Unit, Department of Chemistry and Biology A. Zambelli, University of Salerno, Fisciano, Italy

An effective route for ring-opening copolymerization of $\beta$-butyrolactone (BBL) with

OPEN ACCESS

Edited by:

Pimpa Hormnirun,

Kasetsart University, Thailand

Reviewed by:

Tanin Nanok

Kasetsart University, Thailand

Mina Mazzeo

University of Salerno, Italy

${ }^{*}$ Correspondence:

Vincenzo Venditto

vvenditto@unisa.it

Christophe M. Thomas

christophe.thomas@chimie-paristech.fr

Specialty section: This article was submitted to Catalysis and Photocatalysis, a section of the journa

Frontiers in Chemistry

Received: 22 November 2018 Accepted: 15 April 2019

Published: 22 May 2019

Citation:

Kiriratnikom J, Robert C, Guérineau V, Venditto $V$ and Thomas CM (2019)

Stereoselective Ring-Opening (Co)polymerization of $\beta$-Butyrolactone and $\varepsilon$-Decalactone Using an Yttrium

Bis(phenolate) Catalytic System.

Front. Chem. 7:301.

doi: 10.3389/fchem.2019.00301 $\varepsilon$-decalactone $(\varepsilon-\mathrm{DL})$ is reported. Microstructures of the block copolymers characterized by ${ }^{13} \mathrm{C}$ NMR spectroscopy revealed syndiotactic-enriched poly(3-hydroxybutyrate) (PHB) blocks. Several di- and triblock copolymers (PDL- $b-\mathrm{PHB}$ and PDL- $b-\mathrm{PHB}-b-\mathrm{PDL}$, respectively) were successfully synthesized by sequential addition of the monomers using (salan)Y(III) complexes as catalysts. The results from MALDI-ToF mass spectrometry confirmed the presence of the copolymers. Moreover, thermal properties of the block copolymers were also investigated and showed that the microphase separation of PDL-b-PHB copolymers into PHB- and PDL-rich domains has an impact on the glass transition temperatures of both blocks.

Keywords: yttrium complex, ring-opening copolymerization, $\varepsilon$-decalactone, $\beta$-butyrolactone, tacticity

\section{INTRODUCTION}

Polyhydroxyalkanoates (PHAs) comprise a group of naturally occurring aliphatic polyesters produced by bacteria and other living organisms (Reddy et al., 2003; Tan et al., 2017). These biodegradable and hydrophobic materials combine the film-barrier properties of polyesters with the mechanical performances of petroleum-based polyethylene and polypropylene. Thanks to their interesting properties, these polymers are already used in packaging, automotive, hygienic, agricultural, and biomedical applications (Costa et al., 2013; Khosravi-Darani, 2015; Luef et al., 2015; Ali and Jamil, 2016; Yeo et al., 2018). The most common PHA is poly(3-hydroxybutyrate) (PHB), which is a linear, isotactic, high-molecular-weight polymer. However, this polymer has poor mechanical properties due to its brittleness and a susceptibility to thermal degradation slightly above its melting temperature. Therefore, development of a synthesis method producing PHBs with controlled molecular weight, lower melting temperature, and lower brittleness would be a solution for industrial manufacturing and practical use of ideal bio-based polymers (Li et al., 2016). One of the most effective approaches for the controlled synthesis of $\mathrm{PHB}$ is ring-opening polymerization (ROP) of $\beta$-butyrolactone (BBL) (Kricheldorf and Eggerstedt, 1997; Hori and Hagiwara, 1999; Rieth et al., 2002; Ajellal et al., 2010; Brulé et al., 2011, 2013; Li et al., 2016). ROP of $\beta$-butyrolactone 

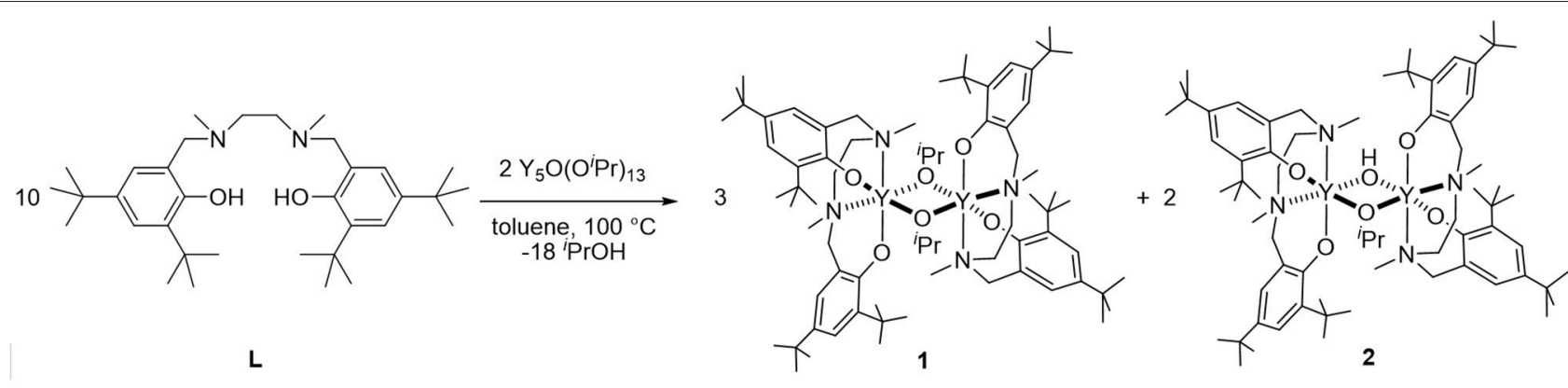

SCHEME 1 | Synthesis of complexes $\mathbf{1}$ and 2.

mediated by metal systems has attracted much attention in recent years and had considerable achievements (Kricheldorf and Eggerstedt, 1997; Hori and Hagiwara, 1999; Rieth et al., 2002; Ajellal et al., 2010; Brulé et al., 2011). A major point of interest for some of these catalysts is the high degree of (stereo)control they exhibit under suitable conditions.

Various modification methods have been reported to improve the performance of PHB (Thomas, 2010; Aluthge et al., 2013; Lin et al., 2013; Olsén et al., 2013; Barouti and Guillaume, 2016). In particular, the formation of PHB-based copolymers might be a promising strategy but still remains a considerable synthetic challenge (Aluthge et al., 2013; Barouti and Guillaume, 2016). In this regard, poly( $\varepsilon$-decalactone) (PDL), a bio-based polymer synthesized by ROP of $\varepsilon$-decalactone ( $\varepsilon$-DL), might be a good candidate to copolymerize with $\mathrm{PHB}$ in order to improve its mechanical properties (Lin et al., 2013; Olsén et al., 2013). Indeed, this polymer has been shown to be amorphous, with a low $T_{\mathrm{g}}$ value (i.e., $-53^{\circ} \mathrm{C}$ ) (Olsén et al., 2013). Although some initiators (co)polymerize $\varepsilon$-decalactone with good control, (Chuang et al., 2013; Lin et al., 2013; Olsén et al., 2013; Jasinska-Walc et al., 2014, 2015; Martello et al., 2014; Schneiderman et al., 2014, 2015; Lee et al., 2015; Zhu et al., 2015, 2018; Mannion et al., 2016; Tang et al., 2017) copolymerization of $\varepsilon$-DL with rac-BBL is still unknown. In this paper, we present the first example of an effective block copolymerization of BBL and DL initiated by a group 3 metal system to produce high-molecular-weight polymers with narrow molecular weight distributions.

\section{RESULTS AND DISCUSSION}

In our search for new copolymerization catalysts, we focused our efforts on investigating the catalytic activity of (salan)Y(III) complexes known to be active for PHB formation (Fang et al., 2013). Therefore, we decided to study the potential of such a catalytic system in a copolymerization procedure, aiming to produce PDL-PHB block copolymers with a one-pot sequential methodology. In accordance with previous observations, the reaction of commercially available $\mathrm{Y}\left(\mathrm{O}^{i} \mathrm{Pr}\right)_{3}$ with the salan ligand $\mathbf{L}$ produces a mixture of bimetallic complexes $\left[(\mathbf{L}) \mathrm{Y}\left(\mu-\mathrm{O}^{i} \mathrm{Pr}\right)\right]_{2}$ (1) and $(\mathbf{L})_{2} \mathrm{Y}_{2}\left(\mu-\mathrm{O}^{i} \mathrm{Pr}\right)(\mu-\mathrm{OH})$ (2) (Scheme 1). Only volatile by-products are then removed between the yttrium alkoxide formation step and the polymerization step so that the resulting complexes are ready for polymerization without purification.

Firstly, we investigated the homopolymerization of $\varepsilon$ decalactone using complexes $\mathbf{1}$ and 2 . The results are summarized in Table 1. These complexes are active initiators for the controlled ROP of $\varepsilon$-DL under mild conditions. The corresponding polymers formed had narrow polydispersities (PDI $\left.=M_{\mathrm{w}} / M_{\mathrm{n}}\right)$, and GPC chromatograms of the isolated polymers are monomodal, suggesting that only one species in solution is active for the ROP of DL (Figure S1). As was already demonstrated for rac-BBL (Fang et al., 2013), we hypothesize that excess monomer cleaves the dimeric structure of both yttrium alkoxide complexes. When these species are exposed to excess DL, the monomer is coordinated and allows the formation of a mononuclear (salan) $\mathrm{Y}\left(\mathrm{O}^{i} \mathrm{Pr}\right)(\mathrm{DL})$ complex and a (salan) $\mathrm{Y}(\mathrm{OH})(\mathrm{DL})$ species, presumably inactive for polymerization.

The resulting catalytic system proved to be active at $50^{\circ} \mathrm{C}$ in either $\mathrm{C}_{6} \mathrm{D}_{6}$ or toluene solutions. For $[\mathrm{DL}] /[\mathrm{Y}]=62.5$, polymerization in $\mathrm{C}_{6} \mathrm{D}_{6}$ reached $92 \%$ conversion in $10 \mathrm{~h}$ (Table 1, Entry 2), while polymerization in toluene achieved $80 \%$ conversion within $14 \mathrm{~h}$ (Table 1, Entry 3). Reducing or increasing the monomer concentration resulted in no significant change of the polymerization control (Table 1, Entries 3 and 4). Although our yttrium-based system was also active at $50^{\circ} \mathrm{C}$ in neat $\mathrm{DL}$, low catalytic activities were observed, probably due to viscosity issues (Table 1, Entry 5) (Moritz, 1989). All other polymerization reactions were therefore preferably conducted in $\mathrm{C}_{6} \mathrm{D}_{6}$ at $[\varepsilon-\mathrm{DL}]=2.5 \mathrm{M}$. Interestingly, this system proved to be active in the presence of 125625 equiv. of lactone (Table 1, Entries 6-8), resulting in a TOF of $6 \mathrm{~h}^{-1}$.

For $[\mathrm{DL}] /[\mathrm{Y}]<100$, the polymers produced have narrow molecular weight distributions and experimental numberaverage molecular masses $\left(M_{\mathrm{n}}\right)$ close to the theoretical ones. However, for higher ratios, experimental $M_{\mathrm{n}}$ values do not correspond well with calculated $M_{\mathrm{n}}$ values. This mismatch possibly arises from suppression of hydrodynamic volume of PDL chains in THF or poor correlation between the polystyrene calibration of the GPC and the actual molecular weights of the PDL chains, as already reported by Olsén et al. (2013). 
TABLE 1 | Polymerization of $\varepsilon$-decalactone using (salan)Y(III) complexes $^{\mathrm{a}}$.

\begin{tabular}{|c|c|c|c|c|c|c|c|c|}
\hline Entry & {$[\mathrm{DL}] /[\mathrm{Y}]$} & {$[\mathrm{DL}](\mathrm{mol} / \mathrm{L})$} & Solvent & $\operatorname{Time}^{\mathrm{b}}$ (h) & Conv. $^{\mathrm{C}}(\%)$ & $\boldsymbol{M}_{\mathrm{n}, \mathrm{c} \text { calc }}^{\mathrm{d}}$ & $\boldsymbol{M}_{\mathrm{n}, \exp }^{\mathrm{d}}$ & $M_{\mathrm{w}} / M_{\mathrm{n}}^{\mathrm{d}}$ \\
\hline 1 & 31.3 & 2.5 & $\mathrm{C}_{6} \mathrm{D}_{6}$ & 4 & 83 & 4,400 & 7,000 & 1.12 \\
\hline 2 & 62.5 & 2.5 & $\mathrm{C}_{6} \mathrm{D}_{6}$ & 10 & 92 & 9,800 & 10,500 & 1.26 \\
\hline 4 & 62.5 & 5 & Toluene & 14 & 100 & 10,600 & 11,400 & 1.13 \\
\hline 5 & 125 & - & - & 20 & 31 & 6,600 & 7,100 & 1.12 \\
\hline 8 & 625 & 2.5 & $\mathrm{C}_{6} \mathrm{D}_{6}$ & 150 & 61 & 64,900 & 15,600 & 1.08 \\
\hline
\end{tabular}

${ }^{a}$ All reactions performed at $50^{\circ} \mathrm{C}$.

${ }^{b}$ Time was not necessarily optimized.

${ }^{c}$ As determined by the integration of ${ }^{1} H$ NMR methine resonances of $D L$ and $P D L$.

${ }^{d} M_{n}$ and $M_{w} / M_{n}$ of polymer determined by SEC-Rl using polystyrene standards. $\left.M_{n, \text { calc }}=[D L] / Y\right] \times$ Conv. $\times M_{D L}$.

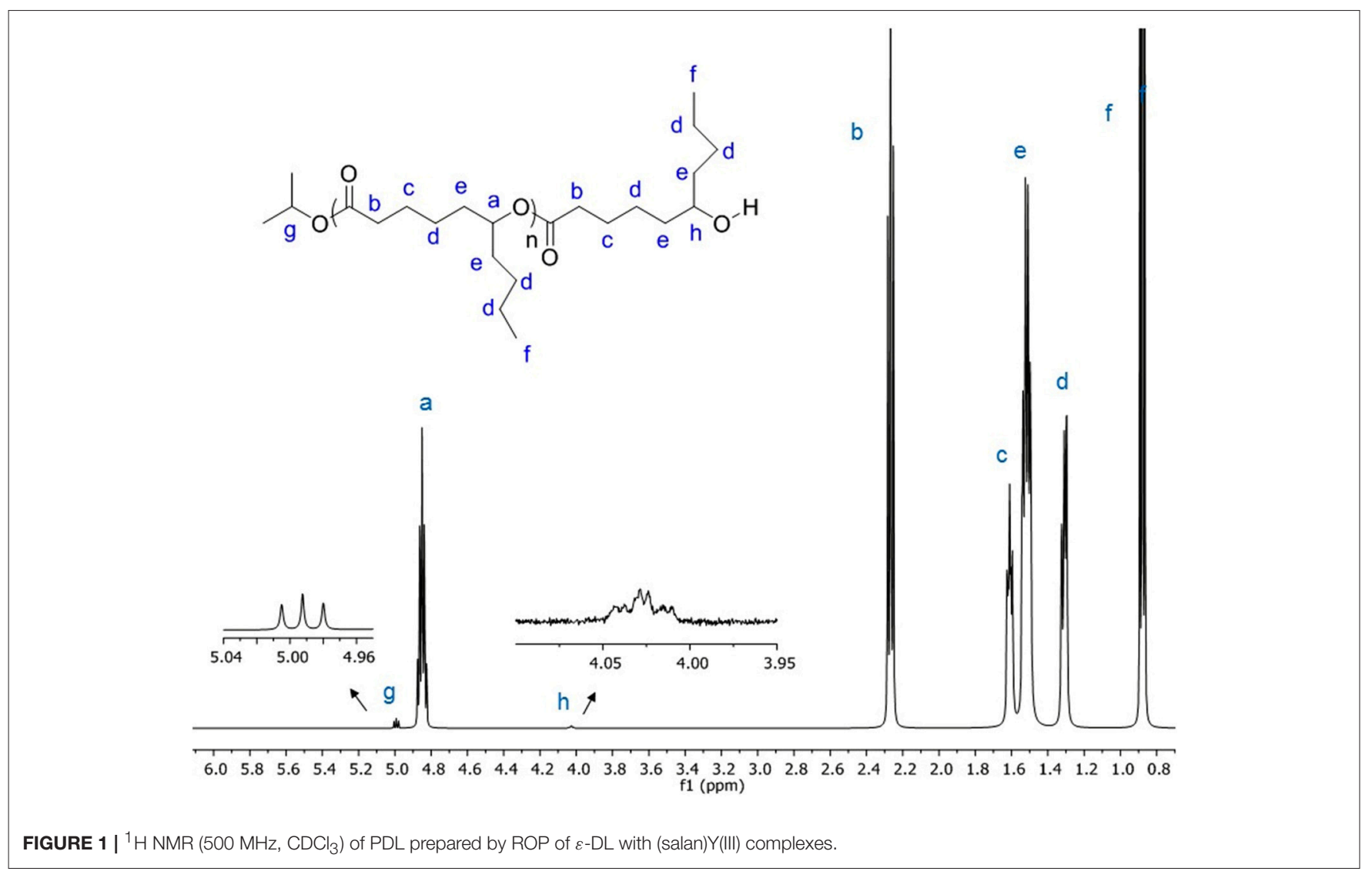

To confirm the mechanism, PDL was characterized by NMR spectroscopy. The results showed the polymer chain having isopropoxide and hydroxyl as end groups (Figure 1 and Figure S2), suggesting that the polymerization occurs through a coordination-insertion mechanism. The mechanism is similar to the mechanism reported in ROP of lactones or lactide catalyzed by metal alkoxide complexes (Thomas, 2010; Chuang et al., 2013; Fang et al., 2013). Matrix Assisted Laser Desorption Ionisation - Time of Flight (MALDI-ToF) mass spectrometry analysis was also performed in order to determine structure of the resulting polymer. The sample from Table 1, Entry 1, was chosen to be characterized by MALDI-ToF-MS. The spectrum reveals a repeating mass series of linear $\mathrm{PDL}$ having isopropoxide as an end group $\left(\mathrm{O}^{i} \operatorname{Pr}[\varepsilon-\mathrm{DL}]_{\mathrm{n}} \mathrm{H}+\mathrm{Cs}^{+}\right)$(Figure S3). The result is consistent with the end-group analysis by ${ }^{1} \mathrm{H}$ NMR spectroscopy. All of the PDL samples are transparent viscous liquids under ambient temperature, indicating the amorphous nature of PDL (Lin et al., 2013; Olsén et al., 2013). Having an 
TABLE 2 | Copolymerization of $\varepsilon$-DL and BBL using (salan)Y(III) complexes ${ }^{a}$.

\begin{tabular}{|c|c|c|c|c|c|c|c|c|c|c|}
\hline \multirow[t]{2}{*}{ Entry } & \multirow[t]{2}{*}[\mathrm{DL}+\mathrm{BBL}+\mathrm{DL}]{$/[\mathrm{Y}]$} & \multirow[t]{2}{*}{$\varepsilon-\mathrm{DL}^{\mathrm{C}}(\mathrm{mol} \%)$} & \multirow[t]{2}{*}{ Solvent } & \multicolumn{2}{|c|}{ Time (min) ${ }^{d}$} & \multicolumn{2}{|c|}{ Conv. $(\%)^{\mathrm{e}}$} & \multirow[t]{2}{*}{$\boldsymbol{M}_{\mathrm{n}, \exp }^{\dagger}$} & \multirow[t]{2}{*}{$M_{\mathrm{n}, \mathrm{calc}}^{\mathrm{f}}$} & \multirow[t]{2}{*}{$M_{\mathrm{w}} / M_{\mathrm{n}}^{\mathrm{f}}$} \\
\hline & & & & $\varepsilon-\mathrm{DL}$ & BBL & $\varepsilon-\mathrm{DL}$ & BBL & & & \\
\hline 1 & $12.5+12.5+0$ & 46 & $\mathrm{C}_{6} \mathrm{D}_{6}$ & 210 & 15 & 86 & 99 & 4,100 & 2,900 & 1.25 \\
\hline 2 & $25+25+0$ & 47 & $\mathrm{C}_{6} \mathrm{D}_{6}$ & 280 & 10 & 72 & 82 & 7,600 & 4,800 & 1.25 \\
\hline 3 & $10+400+0$ & 5 & Toluene & 180 & 90 & 92 & 47 & 11,100 & 17,800 & 1.22 \\
\hline $4^{b}$ & $20+380+0$ & 8 & Toluene & 240 & 540 & 96 & 58 & 8,400 & 22,200 & 1.35 \\
\hline $5^{b}$ & $40+360+0$ & 14 & Toluene & 540 & 510 & 98 & 66 & 12,000 & 27,200 & 1.26 \\
\hline $6^{b}$ & $80+320+0$ & 25 & Toluene & 1,080 & 480 & 92 & 69 & 15,000 & 31,600 & 1.37 \\
\hline $7^{\mathrm{b}}$ & $200+200+0$ & 59 & Toluene & 2,640 & 1,020 & 86 & 60 & 14,700 & 39,600 & 1.23 \\
\hline 8 & $12.5+12.5+12.5$ & 55 & $\mathrm{C}_{6} \mathrm{D}_{6}$ & 330 & 15 & 61 & 99 & 4,500 & 3,700 & 1.17 \\
\hline 9 & $25+25+25$ & 51 & $\mathrm{C}_{6} \mathrm{D}_{6}$ & 280 & 10 & 52 & 99 & 8,200 & 6,600 & 1.15 \\
\hline
\end{tabular}

a Polymerization of $\varepsilon-D L$ and $B B L$ were respectively performed at $50^{\circ} \mathrm{C}$ and room temperature with $[D L]=2.5$ mol/L, unless otherwise stated.

${ }^{b}[D L+B B L]=2.5 \mathrm{~mol} / \mathrm{L}$.

${ }^{c} D L$ content in copolymer.

${ }^{d}$ Time was not necessarily optimized.

${ }^{e}$ As determined by the integration of ${ }^{1} H N M R$ methine resonances of $D L$ and $P D L$.

${ }^{f} M_{n}$ and $M_{w} / M_{n}$ of polymer determined by SEC-RI using polystyrene standards. $M_{n}$ values were not corrected. $\left.\left.M_{n, \text { calc }}=[D L] / Y Y\right] \times C o n v . \times M_{D L}+[B B L] / Y\right] \times C o n v . \times M_{B B L}$.

amorphous nature, it could be a great choice to copolymerize PDL with brittle polymers to improve the performance of the resulting copolymer. Then, we investigated the catalytic activity of our yttrium system toward diblock copolymerization of $\varepsilon$ $\mathrm{DL}$ and rac-BBL. The copolymerization was first attempted through addition of monomer mixture to a $\mathrm{C}_{6} \mathrm{D}_{6}$ solution of the precursor at $60^{\circ} \mathrm{C}$. However, this method failed to give block copolymers, as GPC analysis showed multimodal distributions. The copolymerization was therefore carried out by one-pot sequential copolymerization of first $\varepsilon$-DL and then rac-BBL at room temperature. The results are summarized in Table 2. For [monomers] $/[\mathrm{Y}]<100$, the copolymerization nearly reached completion for both monomers in $<5 \mathrm{~h}$ in $\mathrm{C}_{6} \mathrm{D}_{6}$ (Table 2, Entries 1 and 2). By doubling the monomer-to-metal ratio, the resultant polymer revealed a double experimental $M_{n}$ value, indicating a controlled polymerization reaction (Table 2, Entries 1 and 2 ). The copolymerization was then conducted in toluene with high amounts of rac-BBL (Table 2, Entries 3-7). The resulting copolymers having 5-59 mol\% of $\varepsilon$-DL were synthesized with TOF up to $44 \mathrm{~h}^{-1}$. Interestingly, the catalytic system also proved to be active for synthesizing PDL- $b$-PHB- $b$-PDL triblock copolymers by one-pot sequential copolymerization. The copolymerization achieved $\sim 60 \%$ conversion of $\varepsilon$-DL and $99 \%$ conversion of rac-BBL (Table 2, Entries 8 and 9). GPC analysis of all the copolymers showed a monomodal peak with narrow molecular weight distributions $M_{\mathrm{w}} / M_{\mathrm{n}}$ (Figure S1). As observed for the homopolymerization of $\varepsilon$-DL, lower experimental $M_{\mathrm{n}}$ values were obtained, probably due to poor correlation between the polystyrene calibration of the GPC and the actual molecular weights. In order to determine the diffusion coefficients of two copolymers of different sizes (Table 2, Entries 1 and 7), DOSY NMR experiments were performed. For the low-molecularweight copolymer sample (Table 2, Entry 1), we measured a diffusion coefficient of $2.32 \times 10^{-10} \mathrm{~m}^{2} \cdot \mathrm{s}^{-1}$, while the higher-molecular-weight copolymer corresponded to a diffusion coefficient of $1.88 \times 10^{-10} \mathrm{~m}^{2} \cdot \mathrm{s}^{-1}$ (Table 2, Entry 7). As the rate of diffusion is inversely related to the molecular weight/size, these results are consistent with GPC analyses (Figures S12, S13).

In order to determine topology and end groups of the block copolymers, a diblock copolymer (PDL- $b$-PHB) (Table 2, Entry 1 ) and a triblock copolymer (PDL- $b$-PHB- $b$-PDL) (Table 2, Entry 8) were characterized by MALDI-ToF-MS (Figure 2 and Figure S4). The highest-intensity isotope distribution corresponds to linear PDL with an isopropoxide end group. Also, analysis of the minor isotope distributions confirmed the presence of the block copolymers. For instance, in Figure 2, the peak at $\mathrm{m} / \mathrm{z} 1,980.31$ corresponds to $\left(\mathrm{O}^{i} \operatorname{Pr}[\varepsilon-\mathrm{DL}]_{10}[\mathrm{BBL}]_{1} \mathrm{H}\right.$ $+\mathrm{Cs}^{+}$). Similar MALDI-ToF-MS spectra showing minor series of isotope distribution of block copolymers were previously reported for $\operatorname{poly}(\varepsilon$-decalactone $)-b$-poly ( $\omega$-pentadecalactone) copolymers (Jasinska-Walc et al., 2015). For PDL- $b$-PHB- $b$-PDL, similar isotope patterns are observed with mass higher than PDL- $b$-PHB (Figure S4).

\section{Microstructural and Statistical Analysis of the Copolymers}

Microstructural analysis of PDL- $b$-PHB was studied by ${ }^{13} \mathrm{C}$ NMR spectroscopy. The resonances were assigned at the diad and triad levels. Ring-opening copolymerization of $\varepsilon$-DL and rac$\mathrm{BBL}$ promoted by the yttrium complexes allowed the formation of syndiotactic PHB in PDL- $b$-PHB copolymers. By comparing ${ }^{13} \mathrm{C} \mathrm{NMR}$ of the block copolymers with a prior ${ }^{13} \mathrm{C} \mathrm{NMR}$ assignment for syndiotactic PHBs (Ajellal et al., 2009a; Fang et al., 2013), expansion of both carbonyl and methylene regions of PHB in PDL- $b$-PHB copolymer showed resonances that corresponded to triad sensitivities. The most intense resonances of the carbonyl and methylene regions at $\delta 169.32$ and $\delta 40.79$ ppm, respectively, were correlated to $r r$-centered triads. The lower-intensity resonances at $\delta 169.22$ (carbonyl region) and $\delta$ $40.93 \mathrm{ppm}$ (methylene region) were assigned to $\mathrm{rm}$ triads, and 


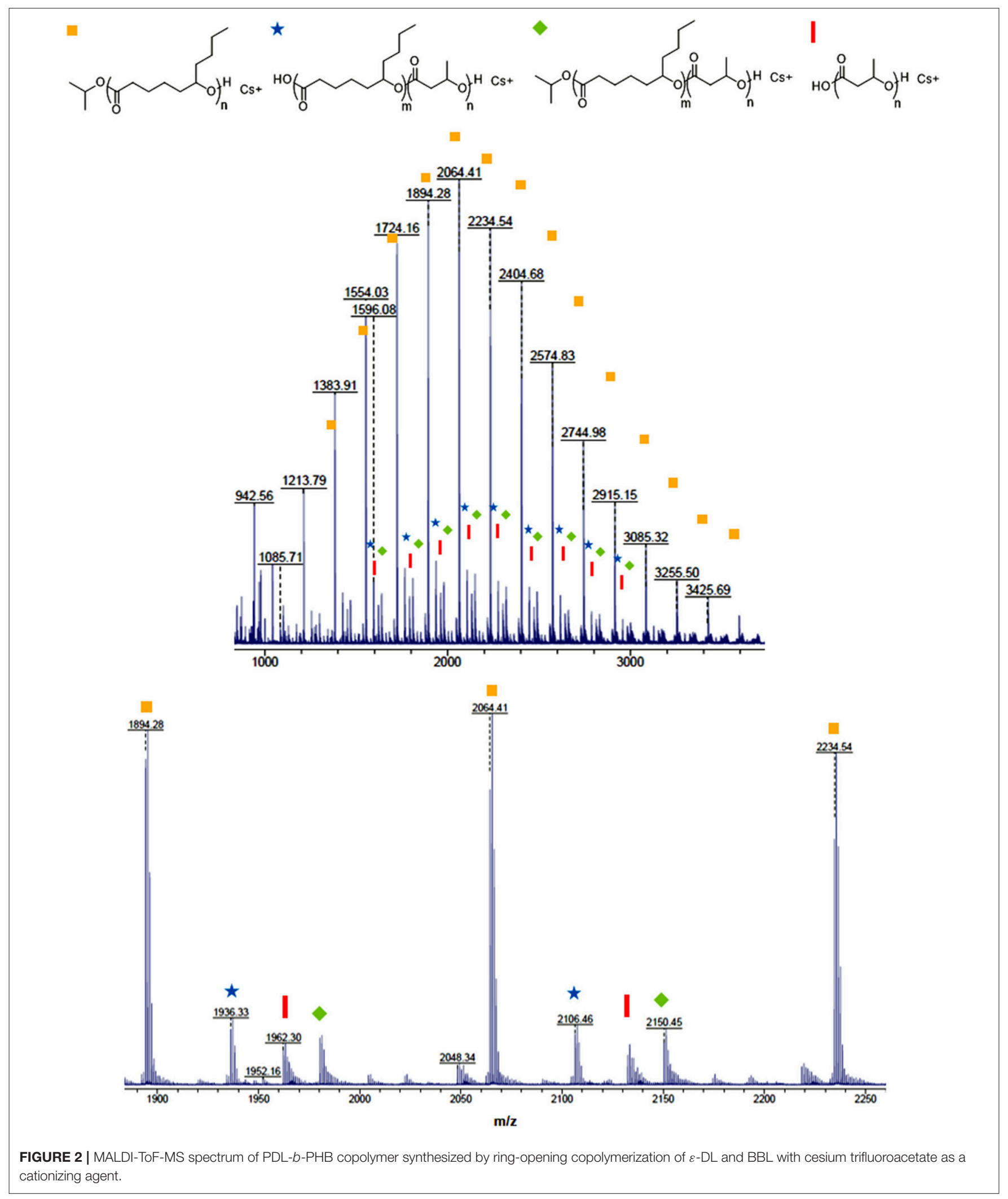




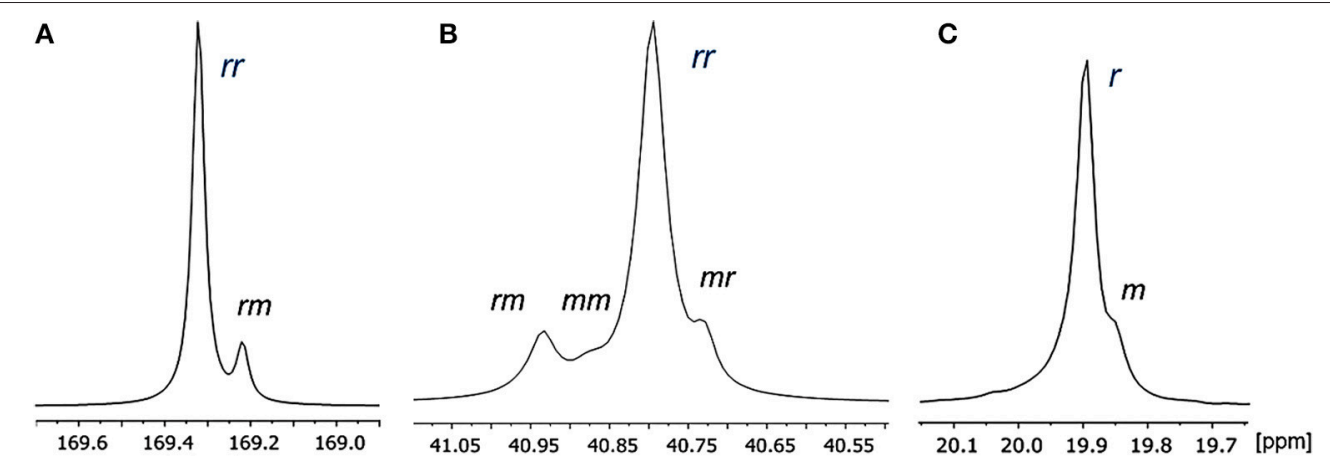

FIGURE 3 $\left.\right|^{13} \mathrm{C}$ NMR spectrum (125 MHz, CDCl 3 ) of (A) carbonyl region and (B) methylene region, (C) methyl region of PHB in PDL-b-PHB copolymers (Table 2, entry 6).

the others at $\delta 40.88$ and $\delta 40.73$ (methylene region) were $\mathrm{mm}$ and $m r$ triads, respectively (Figure 3 ).

Notably, the resonance attributed to $\mathrm{mm}$ triad is almost negligible, as expected for syndiotactic-enriched polymers (Amgoune et al., 2006; Ajellal et al., 2009a,b). The methyl region shows two resonances at the diad level. The resonance at $\delta 19.89 \mathrm{ppm}$ was correlated to $r$ diad, and the one at $\delta 19.84 \mathrm{ppm}$ was assigned to $m$ diad. Therefore, probability of racemic linkages between monomer units $\left(P_{\mathrm{r}}\right)$ can be calculated (Amgoune et al., 2006; Ajellal et al., 2009a,b). As expected for syndiotactic PHBs, $P_{\mathrm{r}}$ values of $\mathrm{PHB}$ in PDL- $b$-PHB are high (up to 0.90 syndiotacticity), for all diblock copolymers with 5-25 mol\% $\varepsilon$-DL (Table 3, Entries 2-5), although we observed slight differences in the $\mathrm{PHB}$ microstructures depending on the reaction conditions (e.g., the concentration of monomer) (Amgoune et al., 2006; Ajellal et al., 2009b; Kramer et al., 2009). Finally, the microstructure of PDL blocks was not determined, due to insufficient resolution of $\varepsilon$-DL resonances at $125.0 \mathrm{MHz}$ (Figure S5).

\section{Thermal and X-Ray Analyses}

Differential scanning calorimetry (DSC) and wide-angle $\mathrm{x}$ ray diffraction (WAXD) analyses were performed to evaluate the influence of $\varepsilon$-DL content on the thermal and structural properties of the copolymers. The main thermal properties [i.e., glass transition temperatures $\left(T_{\mathrm{g}}\right)$, melting temperatures $\left(T_{\mathrm{m}}\right)$, and melting enthalpies $\left.\left(\Delta H_{\mathrm{m}}\right)\right]$ of the selected PDL$b$-PHB copolymers (corresponding to polymers of Table 2, Entries 3-6) are reported in Table 3. Thermal data of a PHB sample are also shown in Table 3 for comparison. All analyzed samples crystallize from melt during the DSC cooling run, and only small differences are observed for both $T_{\mathrm{m}}$ and $\Delta H_{\mathrm{m}}$ between first and second DSC heating runs. Second DSC heating thermograms of Entries 1-5 in Table 3 are reported in Figures S6-S11.

The detected high values of $T_{\mathrm{m}}$ (ranging from 144 to $156^{\circ} \mathrm{C}$ ) and $\Delta H_{\mathrm{m}}$ (ranging from 42 to $59 \mathrm{~J} / \mathrm{g}$ ) of copolymers are in good agreement with those observed for other syndiotacticenriched PHB homopolymers $\left(0.8<P_{\mathrm{r}}<0.9\right)$ (Ajellal et al., 2009a; Ebrahimi et al., 2016). This hypothesis was confirmed by the WAXD patterns of all copolymers (Figure 4). Positions and intensity ratios of Bragg reflections detected in the spectra correspond to those observed for the syndiotactic $\mathrm{PHB}$ crystalline form (Kemnitzer et al., 1993, 1995). Moreover, WAXD spectra confirm that PDL blocks are amorphous, since no other Bragg reflection, except those of the syndiotactic PHB crystal form, was detected. Both thermal (Table 3) and structural (Figure 4) data suggest that $\varepsilon$-DL content ranging from 5 to $25 \mathrm{~mol} \%$ has less effect on crystallinity of PHB blocks of PDL- $b$-PHB copolymers. It is worth noting that even by increasing $\varepsilon$ DL content to $59 \mathrm{~mol} \%$ (Table 2, Entry 7), the $T_{\mathrm{m}}$ of the PHB block remains high (i.e., $143^{\circ} \mathrm{C}$ ). Based on these data, it appears that the PDL block, probably due to its high flexibility, has no influence on the ability of the PHB block to crystallize.

The observed small differences in $T_{\mathrm{m}}$ of copolymers reported in Table 3 are possibly due to small differences in stereoregularity of the $\mathrm{BBL}$ unit sequences rather than to the PDL block lengths (Figure S14). These differences could explain why, in the second DSC heating run, the copolymer with $25 \mathrm{~mol} \%$ of DL units (Table 3, Entry 5) has a $T_{m}$ higher than the one of the PHB homopolymer having similar $M_{\mathrm{n}}$ (Table 3, Entry 1). In addition, PDL- $b$-PHB copolymers exhibited two $T_{\mathrm{g}}$ values ( $T_{\mathrm{g}}$ values were evaluated by second DSC heating runs and reported in Table 3), one in the range $-5,+4^{\circ} \mathrm{C}$, similar to the $T_{\mathrm{g}}$ of a PHB homopolymer (Ajellal et al., 2009a), and the second in the range $-52,-48^{\circ} \mathrm{C}$, comparable to the $T_{\mathrm{g}}$ of a $\mathrm{PDL}$ homopolymer (Olsén et al., 2013). This probably results in the immiscibility of PHB and PDL blocks (Olsén et al., 2013). In Figure 5, $T_{\mathrm{g}}$ of both PDL and PHB blocks of the polymers reported in Table 3 was plotted as a function of $\varepsilon$-DL mol\% content. A roughly linear behavior for both glass transition temperatures is observed. Therefore, increasing the length of the PDL blocks increases the glass transition temperatures of the PHB blocks while slightly decreasing the ones of the PDL blocks. 

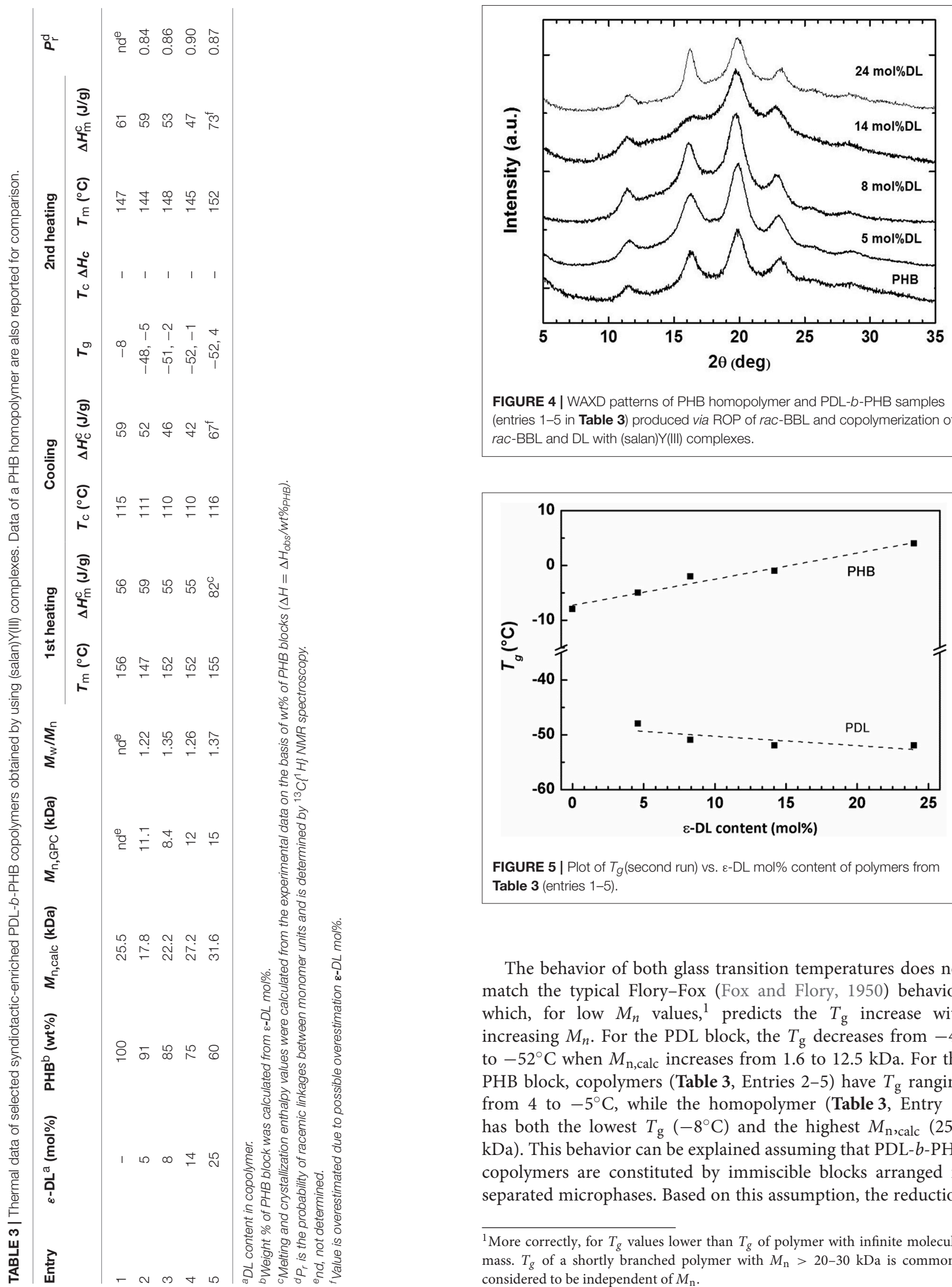

FIGURE 4 | WAXD patterns of PHB homopolymer and PDL- $b$-PHB samples (entries 1-5 in Table 3) produced via ROP of rac-BBL and copolymerization of rac-BBL and DL with (salan)Y(III) complexes.

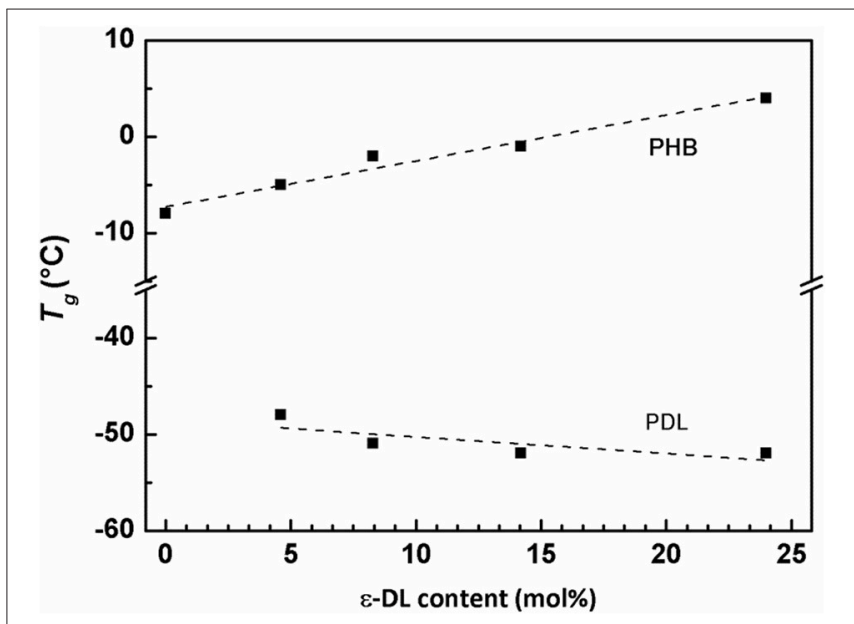

FIGURE 5 | Plot of $T_{g}$ (second run) vs. $\varepsilon$-DL mol\% content of polymers from Table 3 (entries 1-5).

The behavior of both glass transition temperatures does not match the typical Flory-Fox (Fox and Flory, 1950) behavior, which, for low $M_{n}$ values, ${ }^{1}$ predicts the $T_{\mathrm{g}}$ increase with increasing $M_{n}$. For the PDL block, the $T_{\mathrm{g}}$ decreases from -48 to $-52^{\circ} \mathrm{C}$ when $M_{\mathrm{n} \text {,calc }}$ increases from 1.6 to $12.5 \mathrm{kDa}$. For the PHB block, copolymers (Table 3, Entries 2-5) have $T_{\mathrm{g}}$ ranging from 4 to $-5^{\circ} \mathrm{C}$, while the homopolymer (Table 3, Entry 1) has both the lowest $T_{\mathrm{g}}\left(-8^{\circ} \mathrm{C}\right)$ and the highest $M_{\mathrm{n} \text {,calc }}(25.5$ $\mathrm{kDa}$ ). This behavior can be explained assuming that PDL- $b$-PHB copolymers are constituted by immiscible blocks arranged in separated microphases. Based on this assumption, the reduction

\footnotetext{
${ }^{1}$ More correctly, for $T_{g}$ values lower than $T_{g}$ of polymer with infinite molecular mass. $T_{g}$ of a shortly branched polymer with $M_{\mathrm{n}}>20-30 \mathrm{kDa}$ is commonly considered to be independent of $M_{\mathrm{n}}$.
} 
of the volume fraction ${ }^{2}$ of the PHB phase $\left(f_{\mathrm{PHB}}\right)$, which decreases from 0.9 to 0.55 with increasing $\varepsilon$-DL content from 5 to $25 \mathrm{~mol} \%$, corresponds to a size decrease of PHB-rich domains. Moreover, we can also assume that the PHB blocks have a decreasing mobility, as they are segregated in gradually decreasing space and surrounded by an immiscible phase. As it is generally accepted that $T_{\mathrm{g}}$ is inversely related to polymer flexibility and mobility, the observed increase of $T_{\mathrm{g}}$ of PHB can therefore be explained by the reduction of the PHB block mobility due to the microphase separation of PDL- $b$-PHB copolymers into PDL and PHB domains.

For the PDL block, with increasing volume fraction of the PDL phase $\left(f_{\mathrm{PDL}}\right)$, which increases from 0.1 to 0.45 with increasing $\varepsilon$-DL content from 5 to $25 \mathrm{~mol} \%$, the size of PDL-rich domains, increases and the mobility of PDL blocks, segregated into increasing space, is assumed to increase. Consequently, with increasing $f_{\mathrm{PDL}}$, the PDL block mobility increases approaching the mobility of PDL homopolymer, and as a result, $T_{\mathrm{g}}$ of the PDL block approaches that of the homopolymer (i.e., $-53^{\circ} \mathrm{C}$ ) (Olsén et al., 2013).

\section{CONCLUSION}

We have reported for the first time the ring-opening copolymerization of $\varepsilon$-DL with rac-BBL catalyzed by an yttriumbased catalytic system. Di- and triblock copolymers, PDL- $b$-PHB and PDL- $b$-PHB- $b$-PDL, were synthesized by means of one-pot sequential polymerization of $\varepsilon$-DL and rac-BBL. In agreement with NMR observations, thermal and structural analyses of PDL- $b$-PHB copolymers suggested that the observed crystallinity is due to the syndiotactic PHB block. Our results demonstrated that the PHB block crystallizes even in the presence of long,

\footnotetext{
${ }^{2}$ The volume fraction $(f)$, at different $\varepsilon$-DL mol\%, was calculated by using $M_{n \text {.calc }}$ of both polymer blocks and density values of 0.97 and $1.22 \mathrm{~g} / \mathrm{cm}^{3}$ for PDL and PHB blocks, respectively.
}

amorphous, and highly flexible PDL blocks. Moreover, it has been also observed that the microphase separation of PDL$b$-PHB copolymers into PHB- and PDL-rich domains has an impact on the glass transition temperature of both blocks, which is not in agreement with the Flory-Fox relationship. As observed for a thermoplastic elastomer, the physical behavior of these copolymers (i.e., stiffness/flexibility) can be tuned by changing the $\varepsilon$-DL/BBL ratio, thanks to the simultaneous presence of a highly flexible phase (PDL block) associated with a rigid crystalline phase (PHB block). Such tunable physical behavior makes these copolymers industrially relevant.

\section{AUTHOR CONTRIBUTIONS}

JK, VG, and CR performed the experiments. CT, JK, and VV wrote the manuscript with support from the co-authors. All authors analyzed the data, discussed the results, and commented on the manuscript.

\section{ACKNOWLEDGMENTS}

CNRS, ENSCP, and the French Ministry of Research and Higher Education are thanked for financial support of this work. We gratefully acknowledge financial support from Mahidol University, the Royal Golden Jubilee Ph.D. Program (PHD/0106/2556), the Thailand Research Fund, and the French government's contribution to the RGJ-Ph.D. program. CT is grateful to the Institut Universitaire de France.

\section{SUPPLEMENTARY MATERIAL}

The Supplementary Material for this article can be found online at: https://www.frontiersin.org/articles/10.3389/fchem. 2019.00301/full\#supplementary-material

the polymerization of racemic $\beta$-butyrolactone. Angew. Chem. Int. Ed. 45, 2782-2784. doi: 10.1002/anie.200600058

Barouti, G., and Guillaume, S. M. (2016). Polyhydroxybutyrate (PHB)based triblock copolymers: synthesis of hydrophobic PHB/poly(benzyl $\beta$-malolactonate) and amphiphilic $\mathrm{PHB} /$ poly(malic acid) analogues by ring-opening polymerization. Polym. Chem. 7, 4603-4608. doi: 10.1039/C6PY00910G

Brulé, E., Gaillard, S., Rager, M.-N., Roisnel, T., Guérineau, V., Nolan, S. P., et al. (2011). Polymerization of racemic $\beta$-butyrolactone using gold catalysts: a simple access to biodegradable polymers. Organometallics 30, 2650-2653. doi: $10.1021 /$ om200271q

Brulé, E., Guérineau, V., Vermaut, P., Prima, F., Balogh, J., Maron, L., et al. (2013). Polymerization of cyclic esters using N-heterocyclic carbene carboxylate catalysts. Polym. Chem. 4, 2414-2423. doi: 10.1039/c3py 00108c

Chuang, H.-J., Chen, H.-L., Huang, B.-H., Tsai, T.-E., Huang, P.-L., Liao, T.-T., et al. (2013). Efficient zinc initiators supported by NNO-tridentate ketiminate ligands for cyclic esters polymerization. J. Polym. Sci. A Polym. Chem. 51, 1185-1196. doi: 10.1002/pola.26486

Costa, M. M., Cabral-Albuquerque, E. C., Alves, T. L., Pinto, J. C., and Fialho, R. L. (2013). Use of polyhydroxybutyrate and ethyl cellulose for coating of urea granules. J. Agric. Food Chem. 61, 9984-9991. doi: 10.1021/jf401185y 
Ebrahimi, T., Aluthge, D. C., Hatzikiriakos, S. G., and Mehrkhodavandi, P. (2016). Highly active chiral zinc catalysts for immortal polymerization of $\beta$-butyrolactone form melt processable syndio-rich poly(hydroxybutyrate). Macromolecules 49, 8812-8824. doi: 10.1021/acs.macromol.6b01908

Fang, J., Tschan, M. J.-L., Roisnel, T., Trivelli, X., Gauvin, R. M., Thomas, C. M., et al. (2013). Yttrium catalysts for syndioselective $\beta$-butyrolactone polymerization: on the origin of ligand-induced stereoselectivity. Polym. Chem. 4, 360-367. doi: 10.1039/C2PY20590D

Fox, T. G., and Flory, P. J. (1950). Second-order transition temperatures and related properties of polystyrene. I. Influence of molecular weight. J. Appl. Phys. 21, 581-591. doi: 10.1063/1.1699711

Hori, Y., and Hagiwara, T. (1999). Ring-opening polymerisation of $\beta$ butyrolactone catalysed by distannoxane complexes: study of the mechanism. Int. J. Biol. Macromol. 25, 237-245. doi: 10.1016/S0141-8130(99)00038-0

Jasinska-Walc, L., Bouyahyi, M., Rozanski, A., Graf, R., Hansen, M. R., and Duchateau, R. (2015). Synthetic principles determining local organization of copolyesters prepared from lactones and macrolactones. Macromolecules 48, 502-510. doi: 10.1021/ma502262e

Jasinska-Walc, L., Hansen, M. R., Dudenko, D., Rozanski, A., Bouyahyi, M., Wagner, M., et al. (2014). Topological behavior mimicking ethylene-hexene copolymers using branched lactones and macrolactones. Polym. Chem. 5, 3306-3310. doi: 10.1039/C3PY01754K

Kemnitzer, J. E., Gross, R. A., McCarthy, S. P., Liggat, J., Blundell, D. J., and Cox, M. (1995). Crystallization behavior of predominantly syndiotactic poly( $\beta$-hydroxybutyrate). J. Environ. Polym. Degrad. 3, 37-47. doi: $10.1007 / \mathrm{BF} 02067792$

Kemnitzer, J. E., McCarthy, S. P., and Gross, R. A. (1993). Preparation of predominantly syndiotactic poly $\beta$-hydroxybutyrate) by the tributyltin methoxide catalyzed ring-opening polymerization of racemic $\beta$-butyrolactone. Macromolecules 26, 1221-1229. doi: 10.1021/ma00058a004

Khosravi-Darani, K. (2015). Application of poly(hydroxyalkanoate) in food packaging: improvements by nanotechnology. Chem. Biochem. Eng. Q. 29, 275-285. doi: 10.15255/CABEQ.2014.2260

Kramer, J. W., Treitler, D. S., Dunn, E. W., Castro, P. M., Roisnel, T., Thomas, C. M., et al. (2009). Polymerization of enantiopure monomers using syndiospecific catalysts: a new approach to sequence control in polymer synthesis. J. Am. Chem. Soc. 131, 16042-16044. doi: 10.1021/ja9075327

Kricheldorf, H. R., and Eggerstedt, S. (1997). Polylactones. 41. polymerizations of $\beta$-d,l-butyrolactone with dialkyltinoxides as initiators. Macromolecules 30, 5693-5697. doi: 10.1021/ma970244c

Lee, S., Lee, K., Kim, Y. W., and Shin, J. (2015). Preparation and characterization of a renewable pressure-sensitive adhesive system derived from $\varepsilon$-decalactone, 1-lactide, epoxidized soybean oil, and rosin ester. ACS Sustain. Chem. Eng. 3, 2309-2320. doi: 10.1021/acssuschemeng.5b00580

Li, Z., Yang, J., and Loh, X. J. (2016). Polyhydroxyalkanoates: opening doors for a sustainable future. NPG Asia Mater. 8, e265-e265. doi: 10.1038/am.2016.48

Lin, J. O., Chen, W., Shen, Z., and Ling, J. (2013). Homo- and block copolymerizations of $\varepsilon$-decalactone with L-lactide catalyzed by lanthanum compounds. Macromolecules 46, 7769-7776. doi: 10.1021/ma401218p

Luef, K. P., Stelzer, F., and Wiesbrock, F. (2015). Poly(hydroxy alkanoate)s in medical applications. Chem. Biochem. Eng. Q. 29, 287-297. doi: 10.15255/CABEQ.2014.2261

Mannion, A. M., Bates, F. S., and MacOsko, C. W. (2016). Synthesis and rheology of branched multiblock polymers based on polylactide. Macromolecules 49, 4587-4598. doi: 10.1021/acs.macromol.6b00792

Martello, M. T., Schneiderman, D. K., and Hillmyer, M. A. (2014). Synthesis and melt processing of sustainable poly( $\varepsilon$-decalactone)-block-poly(lactide) multiblock thermoplastic elastomers. ACS Sustain. Chem. Eng. 2, 2519-2526. doi: $10.1021 / \mathrm{sc} 500412 \mathrm{a}$

Moritz, H. U. (1989). Increase in viscosity and its influence on polymerization processes. Chem. Eng. Technol. 12, 71-87. doi: 10.1002/ceat.270120112

Olsén, P., Borke, T., Odelius, K., and Albertsson, A. C. (2013). $\varepsilon$-Decalactone: a thermoresilient and toughening comonomer to poly(L-lactide). Biomacromolecules 14, 2883-2890. doi: 10.1021/bm400733e

Reddy, C. S. K., Rashmi, R. G., and Kalia, V. C. (2003). Polyhydroxyalkanoates: an overview. Bioresour. Technol. 87, 137-146. doi: 10.1016/S0960-8524(02)00212-2

Rieth, L. R., Moore, D. R., Lobkovsky, E. B., and Coates, G. W. (2002). Single-site $\beta$ diiminate zinc catalysts for the ring-opening polymerization of $\beta$-butyrolactone and $\beta$-valerolactone to poly(3-hydroxyalkanoates). J. Am. Chem. Soc. 124, 15239-15248. doi: 10.1021/ja020978r

Schneiderman, D. K., Gilmer, C., Wentzel, M. T., Martello, M. T., Kubo, T. and Wissinger, J. E. (2014). Sustainable polymers in the organic chemistry laboratory: synthesis and characterization of a renewable polymer from $\delta$-decalactone and L-lactide. J. Chem. Edu. 91, 131-135. doi: 10.1021/ ed $400185 u$

Schneiderman, D. K., Hill, E. M., Martello, M. T., and Hillmyer, M. A. (2015) Poly(lactide)-block-poly( $\varepsilon$-caprolactone-co- $\varepsilon$-decalactone)-block-poly(lactide) copolymer elastomers. Polym. Chem. 6, 3641-3651. doi: 10.1039/C5PY00202H

Tan, D., Yin, J., and Chen, G. Q. (2017). "Production of polyhydroxyalkanoates," in Current developments in biotechnology and bioengineering: production, isolation and purification of industrial products, eds A. Pandey, S. Negi, and C. R. Soccol (Cambridge, MA: Elsevier), 655-692. doi: 10.1016/B978-0-444-63662-1.00029-4

Tang, B., Schneiderman, D. K., Zare Bidoky, F., Frisbie, C. D., and Lodge, T. P. (2017). Printable, degradable, and biocompatible ion gels from a renewable aba triblock polyester and a low toxicity ionic liquid. ACS Macro Lett. 6, 1083-1088. doi: 10.1021/acsmacrolett.7b00582

Thomas, C. M. (2010). Stereocontrolled ring-opening polymerization of cyclic esters: synthesis of new polyester microstructures. Chem. Soc. Rev. 39, 165-173. doi: 10.1039/B810065A

Yeo, J. C. C., Muiruri, J. K., Thitsartarn, W., Li, Z., and He, C. (2018). Recent advances in the development of biodegradable PHB-based toughening materials: approaches, advantages and applications. Mater. Sci. Eng. C Mater. Biol. Appl. 92, 1092-1116. doi: 10.1016/j.msec.2017.11.006

Zhu, Y., Radlauer, M. R., Schneiderman, D. K., Shaffer, M. S. P., Hillmyer, M. A., and Williams, C. K. (2018). Multiblock polyesters demonstrating high elasticity and shape memory effects. Macromolecules 51, 2466-2475. doi: 10.1021/acs.macromol.7b02690

Zhu, Y., Romain, C., and Williams, C. K. (2015). Selective polymerization catalysis: controlling the metal chain end group to prepare block copolyesters. J. Am. Chem. Soc. 137, 12179-12182. doi: 10.1021/jacs.5b04541

Conflict of Interest Statement: The authors declare that the research was conducted in the absence of any commercial or financial relationships that could be construed as a potential conflict of interest.

Copyright (C) 2019 Kiriratnikom, Robert, Guérineau, Venditto and Thomas. This is an open-access article distributed under the terms of the Creative Commons Attribution License (CC BY). The use, distribution or reproduction in other forums is permitted, provided the original author(s) and the copyright owner(s) are credited and that the original publication in this journal is cited, in accordance with accepted academic practice. No use, distribution or reproduction is permitted which does not comply with these terms. 